\title{
Optimizing Fungicide Inputs for Management of Lettuce Drop Caused by Sclerotinia minor and S. sclerotiorum
}

\author{
Michael E. Matheron ${ }^{\dagger}$ and Martin Porchas \\ The University of Arizona, Yuma Agricultural Center, Yuma, AZ 85364
}

Accepted for publication 17 October 2019.

\begin{abstract}
Lettuce drop, caused by the soilborne fungi Sclerotinia minor and $S$. sclerotiorum, continues to be an important disease on this crop in Arizona. Trials were conducted over a 5-year period to compare different fungicides as well as the number, timing, and method of application. Compared with nontreated plots, disease reduction ranging from 49.6 to $61.0 \%$ was achieved on lettuce beds containing S. minor and treated with fluopyram + trifloxystrobin, fluazinam, fluxapyroxad + pyraclostrobin, and boscalid. Treatment of beds containing S. sclerotiorum with Coniothyrium minitans, iprodione, and boscalid reduced lettuce drop from 50.6 to $71.5 \%$. No difference in disease control was noted between one and two applications of boscalid in plots containing either pathogen. In the presence of
\end{abstract}

Abstract

S.

S. minor, beginning the first of two applications of boscalid after seeding did not differ from starting after thinning; however, in plots containing S. sclerotiorum, starting application after seeding was superior to beginning after thinning. Physical incorporation of soil treated with boscalid to a depth of $5.0 \mathrm{~cm}$ did not differ from soil treatment without incorporation in plots containing $S$. minor or $S$. sclerotiorum. On the other hand, in beds containing S. sclerotiorum, incorporation of soil treated with iprodione improved disease control compared with no incorporation.

Keywords: Sclerotinia minor, Sclerotinia sclerotiorum, Lactuca sativa, lettuce, fungicide
Lettuce drop is a major disease of this crop, first described in 1890 on lettuce in the United States (Wu and Subbarao 2017) and first reported in Arizona in 1925 (Brown and Butler 1936). The disease is caused by the soilborne fungi Sclerotinia minor Jagger and S. sclerotiorum (Lib.) de Bary, both of which occur in Arizona lettuce production fields. Lettuce (Lactuca sativa L.) has become a major vegetable crop in southwestern Arizona (Yuma County) and southeastern California (Imperial County), starting with initial seeding in late August and ending with final harvest in early April (Kerns et al. 1999). From November through March, 80 to $90 \%$ of total lettuce production in the United States is harvested from this desert production region. From mid-November through mid-March, lettuce drop can cause losses exceeding 75\% in Arizona (Matheron and Porchas 2016). Similar losses were noted in California (Koike et al. 2007) in some severely infested fields.

Development of disease is initiated by infection of leaves and stems in contact with soil containing either pathogen, resulting in a brown soft decay followed by wilting of outer leaves and final collapse and death of the entire plant. S. sclerotiorum can also infect upper plant parts by production of aerially dispersed ascospores. Lettuce drop often develops when plants are well developed and approaching maturity (Koike et al. 2007). Sclerotia 0.5 to 2 and 5 to $10 \mathrm{~mm}$ long are formed on plants infected with $S$. minor and S. sclerotiorum, respectively. The presence of sclerotia and white mycelium on decayed crown, leaf, and

${ }^{\dagger}$ Corresponding author: M. E. Matheron; matheron@ag.arizona.edu

Funding: This work was funded by the Arizona Iceberg Lettuce Research Council.

The author(s) declare no conflict of interest.

(C) 2019 The American Phytopathological Society taproot tissue are useful features for identifying lettuce drop in the field. Following harvest, crop residue and sclerotia produced on infected lettuce plant tissue are incorporated into soil by disking, followed by planting of crops such as wheat or Sudan grass on nonbedded soil or cotton, melons, or other crops on newly constructed beds. Lettuce planted the following vegetable production season can then be infected by surviving sclerotia, perpetuating the disease.

Lettuce drop management tactics include use of fields not known to have been affected by lettuce drop or rotation from land previously planted to lettuce in which disease developed into other vegetable crops such as broccoli, cauliflower, cabbage, and spinach. However, according to 2018 data, land used for lettuce production in Arizona $(32,250 \mathrm{ha})$ greatly exceeds land used for broccoli, cauliflower, and cabbage (9,040 ha) and spinach (5,300 ha), limiting the use of crop rotation as a lettuce drop management tool. Another useful tool for lettuce drop management in Arizona is flooding fields during the summer for a 2- to 3-week period, which virtually eliminates viable sclerotia of $S$. minor and S. sclerotiorum from infested soil (Matheron and Porchas 2018); however, this cultural management technique has limitations as well. Application of fungicides remains a critical tool for management of lettuce drop in commercial lettuce production. Fungicide applications typically are made to the soil surface to prevent sclerotia germination and infection of plant parts in contact with soil; therefore, treatments are initiated at seeding or after thinning to get maximum coverage of soil. However, the highest degree of disease reduction achieved in past fungicide efficacy trials, compared with nontreated plants, usually ranged from 50 to $60 \%$ (Matheron and Matejka 1989; Matheron and Porchas 2004, 2016, 2017). It is known that effectiveness of lettuce drop management can be dependent on the specific active ingredient(s) within each fungicide product as well as the specific Sclerotinia species present in the field, as shown in the referenced efficacy trials. 
Questions concerning the possible effects of timing and method of fungicide application on disease control have been posed by growers, pest control advisors, and agrichemical companies, such as (i) whether two applications are more effective than a single application, (ii) whether there is a significant difference between initiating fungicide application at seeding followed by another application after thinning compared with a first application after thinning followed by an additional application 2 weeks later, and (iii) whether a soil surface application followed by incorporation of treated soil into the lettuce bed is superior to soil surface application alone. The objective of this research was to gather and analyze data from five yearly trials to compare the efficacy of 10 different fungicides for management of lettuce drop and to seek answers to questions of concern to clientele. Boscalid and iprodione, which have been used for many years as management tools for lettuce drop in Arizona, were employed to test different application scenarios to determine the most effective and efficient means of application.

\section{Production of Sclerotia and Trial Protocol}

All field trials were conducted at the University of Arizona Yuma Agricultural Center on raised beds artificially infested with sclerotia of $S$. minor or S. sclerotiorum. Sclerotia of both pathogens initially were recovered from naturally infected plants grown in commercial fields in Yuma, AZ. Sclerotia were surface sterilized by agitation in a $0.5 \%$ solution of $\mathrm{NaClO}$ (1:9 dilution of household bleach) for 3 min, rinsed in sterile distilled water, and plated onto potato dextrose agar (PDA). Mycelium from an actively growing colony originating from a sclerotium of $S$. minor or $S$. sclerotiorum was placed on fresh PDA plates. These isolates were used to produce sclerotia applied to beds in all field trials. Sclerotia of $S$. minor were produced on potato cubes prepared by placing 15 to 20 cubes of this substrate (each $1.0 \mathrm{~cm}^{3}$ ) in a series of 125-ml-capacity glass flasks, which were autoclaved for $20 \mathrm{~min}$, allowed to cool to room temperature $\left(25^{\circ} \mathrm{C}\right)$ for $24 \mathrm{~h}$, and then autoclaved again. After cooling to room temperature, the potato tissue within each flask was inoculated with a mycelial disk from an actively growing culture of $S$. minor on PDA. After a 4-week incubation period at $20^{\circ} \mathrm{C}$ in darkness, residual potato tissue was removed from mature sclerotia by washing the contents of each flask in running tap water within a soil sieve. Sclerotia were air dried and stored in the laboratory at room temperature until needed (approximately 2 months later). Sclerotia of $S$. sclerotiorum were produced on barley seed by boiling $5.5 \mathrm{~kg}$ of this material in 15 liters of tap water for 90 min, separating the moist grain from the liquid, and placing $1,000 \mathrm{~cm}^{3}$ of the grain into a series of 2-liter wide-mouth flasks. Flasks were autoclaved for $60 \mathrm{~min}$, allowed to cool to room temperature $\left(25^{\circ} \mathrm{C}\right)$, and then autoclaved again $24 \mathrm{~h}$ later. After flasks had cooled, the grain in each container was inoculated with a mycelial disk from an actively growing culture of $S$. sclerotiorum on PDA. After a 6-week incubation period at $20^{\circ} \mathrm{C}$ in darkness, abundant sclerotia had formed. Contents of each flask were removed, spread out on a clean surface, and allowed to air dry. The mixture of sclerotia and infested grain substrate was stored at room temperature for about 2 months until used as inoculum in field trials.

Crisphead lettuce was used in all field trials. Plantings were initiated in November by direct seeding into double rows $30 \mathrm{~cm}$ apart on beds with $100 \mathrm{~cm}$ between bed centers followed by sprinkler irrigation to germinate seed. Furrow irrigation then was used to grow the plants to maturity. Each treatment was replicated five times in a randomized complete block design. Each replicate plot consisted of a 7.6-m length of bed containing two rows of lettuce. Plants were thinned in December at the three- to four-leaf stage to an approximate spacing of $30 \mathrm{~cm}$. For plots infested with
S. minor, $3.6 \mathrm{~g}$ of sclerotia was distributed evenly on the surface of each plot between the rows of lettuce and incorporated into the top $2.5-\mathrm{cm}$ layer of soil with a hand cultivating tool. Cultivation was not close enough to plants to injure roots. For plots infested with $S$. sclerotiorum, an approximate volume of $240 \mathrm{ml}$ of the dried mixture of sclerotia and infested barley grain was broadcast evenly over the surface of each lettuce plot, again between the rows of lettuce on each bed, and incorporated into soil as described for $S$. minor. Treatment plots were separated by a $1.5-\mathrm{m}$ length of untreated bed within the bed and single nontreated beds between treated beds. Treatments (Table 1) were applied to the surface of the bed and plants using a tractor-mounted boom sprayer equipped with flat-fan nozzles spaced $30 \mathrm{~cm}$ apart that delivered 473 liters of spray mixture per hectare at $690 \mathrm{kPa}$. The rate of fungicide applied per treatment was either the maximum allowed on the label for registered materials or the maximum recommended rate for products not registered. The severity of disease was determined at plant maturity in March by recording the number of dead and dying plants in each plot resulting from infection by $S$. minor and S. sclerotiorum. Data are presented as the percent reduction of diseased plants compared with those in nontreated control plots. Analysis of variance of fungicide efficacy trial data was performed with the GLM procedure within CoStat statistical software (CoHort Software, Monterey, CA), and means were separated at $P=0.05$ according to Fisher's protected least significance difference test. Statistical analysis of two treatment data sets was accomplished using Student's $t$ test within SigmaPlot software (Systat Software, San Jose, CA). In all trials, values for each year were treated as replicates when analyzing treatment data for overall percent reduction of diseased plants compared with nontreated controls.

\section{Effect of Fungicides and Application Parameters on Disease Development}

The mean number of dead and dying lettuce plants in 7.6-m-long plots infested with $S$. minor and S. sclerotiorum and not treated with fungicides ranged from 22 to 36 and 27 to 43, respectively, in yearly trials. The overall 5-year mean number of plants infected with $S$. minor and S. sclerotiorum was 27.6 and 30.8, equivalent to plant losses of 57.2 and $61.6 \%$, respectively. When applied to lettuce beds after thinning and again 2 weeks later, significant differences in effectiveness were detected among 10 fungicides in four of five and five of five individual trials in plots containing Sclerotinia minor and S. sclerotiorum, respectively (Table 2). In the presence of $S$. minor, the overall percent disease control for five trials was statistically greatest with $61.0,56.6,54.8$, and $49.6 \%$ when subsequently treated after thinning and again 2 weeks later with fluopyram + trifloxystrobin, fluazinam, fluxapyroxad + pyraclostrobin, and boscalid. For $S$. sclerotiorum, the highest reduction of disease of $71.5 \%$ in the same trials was recorded for plants treated with Coniothyrium minitans (Table 2). Disease reduction of over $50 \%$ also was achieved in the presence of S. sclerotiorum on lettuce treated with iprodione and boscalid. For the combined 5-year period, a significant difference in efficacy in the presence of $S$. minor compared with $S$. sclerotiorum was detected among four of 10 fungicides evaluated. Disease control was significantly greater when fluopyram + trifloxystrobin or penthiopyrad were applied to plots containing $S$. minor compared with those with $S$. sclerotiorum (Table 2). On the other hand, disease control was significantly greater when $C$. minitans or iprodione were applied to plots containing $S$. sclerotiorum compared with $S$. minor.

A significant difference in control of lettuce drop was not detected when comparing one application of boscalid after thinning to an application after thinning followed by a second application 
2 weeks later in yearly trial data for $S$. minor and in only one of five yearly trials for $S$. sclerotiorum (Table 3 ). Considering overall 5-year data for either pathogen, there was no difference in percent disease control between one and two applications of boscalid. Application of boscalid to plots containing S. minor following seeding and again after thinning did not significantly increase disease control compared with application after thinning followed by another application 2 weeks later (Table 4). However, in plots containing $S$. sclerotiorum, initial application of boscalid after seeding provided better disease control compared with starting

\begin{tabular}{|c|c|c|c|c|}
\hline Active ingredient (rate of formulated product) & Product name & FRAC code ${ }^{y}$ & Source & $\begin{array}{l}\text { Application rate } \\
\text { per hectare }\end{array}$ \\
\hline Boscalid (700 g/kg) & Endura & 7 & BASF Ag Products & $780 \mathrm{~g}$ \\
\hline Coniothyrium minitans $(53 \mathrm{~g} / \mathrm{kg})$ & Contans & $\ldots$ & Sipcam Agro USA & $4,540 \mathrm{~g}$ \\
\hline Fluazinam ( $500 \mathrm{~g} /$ liter $)$ & Lektivar & 29 & AgBiome Innovations & $1,774 \mathrm{ml}$ \\
\hline Fluxapyroxad (251 g/liter) + pyraclostrobin ( $251 \mathrm{~g} /$ liter $)$ & Merivon & $7+11$ & BASF Ag Products & $813 \mathrm{ml}$ \\
\hline Iprodione $(480 \mathrm{~g} / \mathrm{liter})$ & Rovral & 2 & FMC Corporation & $2,365 \mathrm{ml}$ \\
\hline Isofetamid (400 g/liter) & Kenja & 7 & Summit Agro USA & $909 \mathrm{ml}$ \\
\hline Mandestrobin $(500 \mathrm{~g} / \mathrm{kg})$ & S2200 & 11 & Valent USA & $851 \mathrm{~g}$ \\
\hline Penthiopyrad (201 g/liter) & Fontelis & 7 & Corteva Agriscience & $1,774 \mathrm{ml}$ \\
\hline
\end{tabular}

${ }^{y}$ FRAC codes from the Fungicide Resistance Action Committee.

${ }^{\mathrm{z}}$ Amount of formulated product applied to plots.

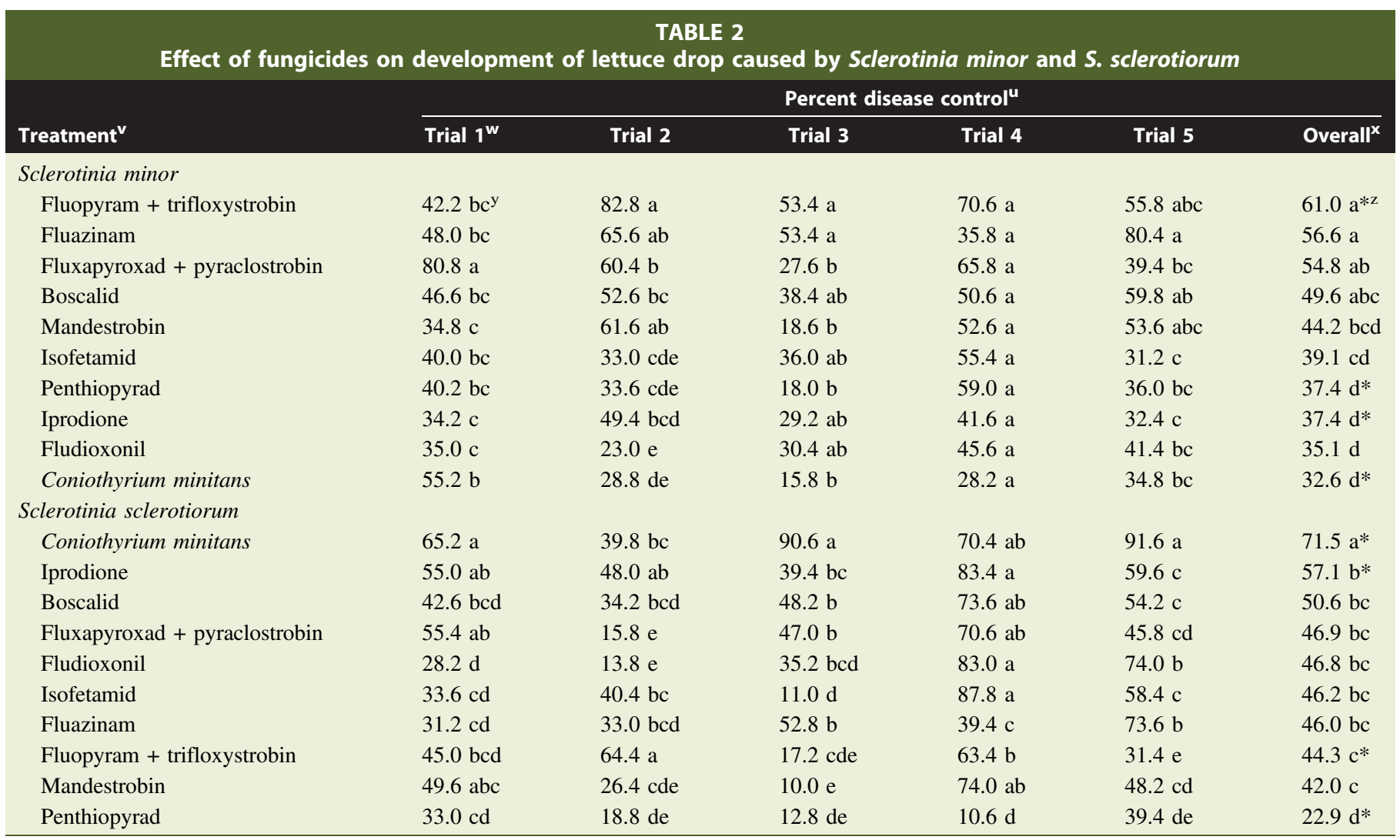

" Percent disease control compared with nontreated plants.

${ }^{v}$ Sclerotia incorporated into lettuce beds after thinning. Fungicide application to bed surface and plants made after thinning and 2 weeks later at rates provided in Table 1.

${ }^{w}$ Yearly field trials conducted from 2010 through 2014.

${ }^{x}$ Overall percent disease control is the mean value of the five trials.

${ }^{\text {y }}$ For each species of Sclerotinia, numbers in each column for treatments followed by a different letter are significantly different $(P=0.05)$ according to the least significant difference test.

z Values for overall percent disease control followed by an asterisk (*) are significantly different from the corresponding value for the same fungicide in plots infested with $S$. sclerotiorum according to Student's $t$ test. $P$ values for fluopyram + trifloxystrobin, penthiopyrad, iprodione, and $C$. minitans were $0.012,0.016,0.002$, and $<0.001$, respectively. 
application after thinning in two of five individual trials and for the entire 5-year evaluation period.

Physical incorporation of soil treated with boscalid to a depth of $5.0 \mathrm{~cm}$ was not better than soil treatment without incorporation considering yearly or 5-year combined data for management of lettuce drop caused by $S$. minor or S. sclerotiorum (Table 5). However, in plots containing $S$. minor and treated with iprodione, incorporation of treated soil to a depth of $5.0 \mathrm{~cm}$ resulted in significantly less control of lettuce drop in one of five yearly trials (Table 6). Also, in the presence of $S$. sclerotiorum, incorporation of soil treated with iprodione increased the percent disease control compared with treatment without incorporation in one of five yearly trials as well as for the overall 5-year trial period.

\section{Lettuce Drop Management Considerations and Conclusions}

The characteristic symptoms of lettuce drop, including a brown soft decay followed by wilting of outer leaves leading to final collapse and plant death, are caused by both $S$. minor and
S. sclerotiorum. However, differences exist between the two pathogens with respect to size of sclerotia, sexual spore production, and method of infecting plants. Sclerotia of $S$. minor, which range from 0.5 to $2 \mathrm{~cm}$ in diameter, are much smaller than those produced by $S$. sclerotiorum, which can range from 5 to $10 \mathrm{~cm}$ in diameter and are irregularly shaped. S. minor rarely produces apothecia and sexual spores from sclerotia; therefore, plant infection occurs by eruptive germination of sclerotia $(\mathrm{Wu}$ and Subbarao 2017). Mycelium from a single sclerotium can infect and kill a lettuce plant (Imolehin and Grogan 1980). Sclerotia of $S$. minor deeper than $8 \mathrm{~cm}$ do not germinate, and those further away than $2 \mathrm{~cm}$ from a lettuce root generally do not initiate infections (Imolehin and Grogan 1980). In comparison, sclerotia of $S$. sclerotiorum commonly germinate carpogenically, producing apothecia and ascospores. This type of germination is favored when sclerotia are 2 to $3 \mathrm{~cm}$ below the soil surface, temperatures are 11 to $20^{\circ} \mathrm{C}$, and soil matric potentials range from -0.03 to $-0.07 \mathrm{MPa}$ (Hao et al. 2003; Wu and Subbarao 2017). In Arizona, infection of lettuce plants in commercial fields by ascospores of $S$. sclerotiorum does occur. On the other

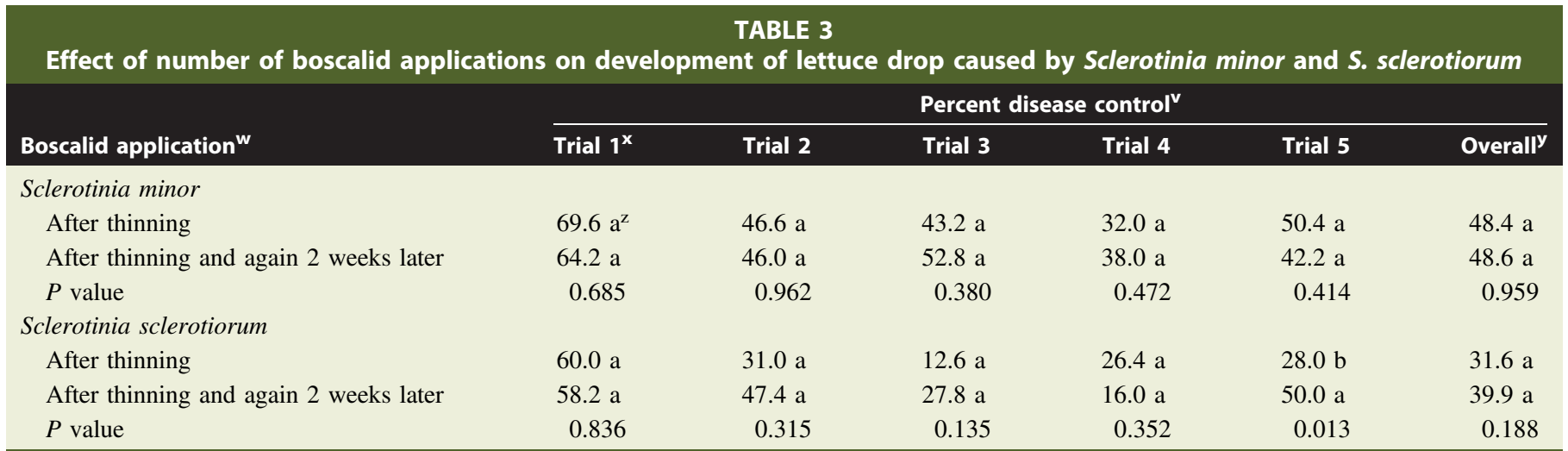

${ }^{v}$ Percent disease control compared with nontreated plants.

${ }^{\mathrm{w}}$ Sclerotia incorporated into lettuce beds after thinning. Boscalid applied to bed surface and plants either after thinning or after thinning and 2 weeks later at rates provided in Table 1.

x Yearly field trials conducted in 2007, 2010, 2011, 2012, and 2014.

y Overall percent disease control is the mean value of the five trials.

${ }^{\mathrm{z}}$ For each species of Sclerotinia, numbers in each column followed by a different letter are significantly different according to Student's $t$ test.

\begin{tabular}{|c|c|c|c|c|c|c|}
\hline \multicolumn{7}{|c|}{$\begin{array}{c}\text { TABLE } 4 \\
\text { Effect of timing of boscalid applications on development of lettuce drop caused by Sclerotinia minor and S. sclerotiorum }\end{array}$} \\
\hline \multirow[b]{2}{*}{ Boscalid applicationw } & \multicolumn{6}{|c|}{ Percent disease controlv } \\
\hline & Trial $\mathbf{1}^{\mathrm{x}}$ & Trial 2 & Trial 3 & Trial 4 & Trial 5 & Overally \\
\hline \multicolumn{7}{|l|}{ Sclerotinia minor } \\
\hline After seeding and thinning & $71.8 \mathrm{a}^{\mathrm{z}}$ & $48.4 \mathrm{a}$ & $43.6 \mathrm{a}$ & $42.4 \mathrm{a}$ & 60.6 a & $55.2 \mathrm{a}$ \\
\hline After thinning and 2 weeks later & $53.4 \mathrm{a}$ & $46.0 \mathrm{a}$ & $52.8 \mathrm{a}$ & $38.0 \mathrm{a}$ & $42.2 \mathrm{a}$ & $46.5 \mathrm{a}$ \\
\hline After seeding and thinning & $76.2 \mathrm{a}$ & $42.0 \mathrm{a}$ & $66.8 \mathrm{a}$ & $55.2 \mathrm{a}$ & $64.0 \mathrm{a}$ & $60.8 \mathrm{a}$ \\
\hline After thinning and 2 weeks later & $47.6 \mathrm{a}$ & $47.4 \mathrm{a}$ & $27.8 \mathrm{~b}$ & $16.0 \mathrm{~b}$ & $50.0 \mathrm{a}$ & $37.8 \mathrm{~b}$ \\
\hline$P$ value & 0.051 & 0.683 & 0.004 & 0.010 & 0.114 & $<0.001$ \\
\hline
\end{tabular}

${ }^{v}$ Percent disease control compared with nontreated plants.

${ }^{\mathrm{w}}$ Sclerotia incorporated into lettuce beds after seeding or after thinning. Boscalid applied to bed surface and plants after seeding and after thinning or after thinning and 2 weeks later at rate provided in Table 1.

$\mathrm{x}$ Yearly field trials conducted from 2009 to 2012 and 2014.

y Overall percent disease control is the mean value of the five trials.

${ }^{\mathrm{z}}$ For each species of Sclerotinia, numbers in each column followed by a different letter are significantly different according to Student's $t$ test. 
hand, infection initiated by eruptive germination is quite common and occurred exclusively in our field trials, perhaps due in part to the infrequent occurrence of extended wet periods with soil moisture near saturation at the 2- to 3-cm depth (Matheron and Porchas 2004).

Differences in the magnitude of disease control provided by some fungicides were apparent when comparing lettuce subjected to infection by $S$. minor or $S$. sclerotiorum. Control of lettuce drop was significantly greater when fluopyram + trifloxystrobin or penthiopyrad was applied to plots containing $S$. minor compared with $S$. sclerotiorum, whereas disease control was significantly greater when $C$. minitans or iprodione was applied to plots containing $S$. sclerotiorum compared with $S$. minor. Comparison of fungicide application methods also revealed some differences in disease control among the two Sclerotinia species. Control of lettuce drop was higher on lettuce beds containing $S$. sclerotiorum, but not $S$. minor, when two applications of iprodione were made to the bed surface and plants followed by incorporation of treated soil into the bed compared with soil application without incorporation. Also, beginning the first of two treatments of boscalid after seeding compared with initiating treatment after thinning increased the degree of disease control in beds containing $S$. sclerotiorum but not $S$. minor. In fields where a single Sclerotinia species is present or predominates, this knowledge can be used to select the most effective fungicide and method of application to maximize control of lettuce drop.

Effective disease management includes use of efficacious fungicides as well as efficient methods of application. However, caution is advised concerning extrapolation of findings concerning the number and timing of applications based on boscalid to other fungicides. The effectiveness of any active ingredient in the field is influenced by several different processes, including but not limited to sorption or movement of the active ingredient and its metabolites, microbial activity, and hydrolytic and photochemical breakdown (Anderson et al. 1999). Furthermore, the factors governing movement and breakdown of a fungicide

\begin{tabular}{|c|c|c|c|c|c|c|}
\hline \multirow{2}{*}{\multicolumn{7}{|c|}{$\begin{array}{l}\text { TABLE } 5 \\
\text { Effect of boscalid application method on development of lettuce drop caused by Sclerotinia } \\
\text { Percent disease controlv }\end{array}$}} \\
\hline & & & & & & \\
\hline \multicolumn{7}{|l|}{ Sclerotinia minor } \\
\hline Bed surface & $65.2 \mathrm{a}^{\mathrm{z}}$ & $60.6 \mathrm{a}$ & $53.4 \mathrm{a}$ & $46.0 \mathrm{a}$ & $52.8 \mathrm{a}$ & $55.4 \mathrm{a}$ \\
\hline Bed surface followed by incorporation & $69.0 \mathrm{a}$ & $69.4 \mathrm{a}$ & $64.8 \mathrm{a}$ & $37.4 \mathrm{a}$ & $44.0 \mathrm{a}$ & $56.9 \mathrm{a}$ \\
\hline \multicolumn{7}{|l|}{ Sclerotinia sclerotiorum } \\
\hline Bed surface & $58.2 \mathrm{a}$ & $50.6 \mathrm{a}$ & $47.6 \mathrm{a}$ & $47.4 \mathrm{a}$ & $27.8 \mathrm{a}$ & $46.3 \mathrm{a}$ \\
\hline Bed surface followed by incorporation & $65.0 \mathrm{a}$ & $62.5 \mathrm{a}$ & $55.8 \mathrm{a}$ & $37.8 \mathrm{a}$ & $33.8 \mathrm{a}$ & $51.5 \mathrm{a}$ \\
\hline$P$ value & 0.505 & 0.175 & 0.532 & 0.487 & 0.501 & 0.359 \\
\hline
\end{tabular}

${ }^{v}$ Percent disease control compared with nontreated plants.

${ }^{w}$ Sclerotia incorporated into lettuce beds after thinning. Applications of boscalid made after thinning and 2 weeks later or same applications made followed by incorporation of treated soil into the bed to a depth of $5 \mathrm{~cm}$. Boscalid applied at rate provided in Table 1.

x Yearly field trials conducted from 2007 to 2011.

y Overall percent disease control is the mean value of the five trials.

${ }^{\mathrm{z}}$ For each species of Sclerotinia, numbers in each column were analyzed for significant difference according to Student's $t$ test. No significant differences were detected in these trials.

\begin{tabular}{|c|c|c|c|c|c|c|}
\hline \multicolumn{7}{|c|}{$\begin{array}{c}\text { TABLE } 6 \\
\text { Effect of iprodione application method on development of lettuce drop caused by Sclerotinia minor and S. sclerotiorum }\end{array}$} \\
\hline Iprodione applicationw & \multicolumn{6}{|c|}{ Percent disease controlv } \\
\hline \multicolumn{7}{|l|}{ Sclerotinia minor } \\
\hline Bed surface & $56.6 \mathrm{a}^{\mathrm{z}}$ & $67.2 \mathrm{a}$ & $46.4 \mathrm{a}$ & $35.0 \mathrm{a}$ & $38.4 \mathrm{a}$ & $47.3 \mathrm{a}$ \\
\hline Bed surface followed by incorporation & $58.0 \mathrm{a}$ & $32.0 \mathrm{~b}$ & $51.8 \mathrm{a}$ & $46.8 \mathrm{a}$ & $30.4 \mathrm{a}$ & $39.0 \mathrm{a}$ \\
\hline \multicolumn{7}{|l|}{ Sclerotinia sclerotiorum } \\
\hline Bed surface & $51.6 \mathrm{a}$ & $47.4 \mathrm{a}$ & $46.4 \mathrm{a}$ & $29.8 \mathrm{~b}$ & $68.2 \mathrm{a}$ & $48.7 \mathrm{~b}$ \\
\hline Bed surface followed by incorporation & $58.4 \mathrm{a}$ & $63.6 \mathrm{a}$ & $51.8 \mathrm{a}$ & $56.2 \mathrm{a}$ & $66.6 \mathrm{a}$ & $59.3 \mathrm{a}$ \\
\hline$P$ value & 0.569 & 0.073 & 0.719 & 0.016 & 0.885 & 0.047 \\
\hline
\end{tabular}

${ }^{\mathrm{v}}$ Percent disease control compared with nontreated plants.

${ }^{\mathrm{w}}$ Sclerotia incorporated into lettuce beds after thinning. Applications of iprodione made after thinning and 2 weeks later or same applications made followed by incorporation of treated soil into the bed to a depth of $5 \mathrm{~cm}$. Iprodione applied at rate provided in Table 1 .

$x$ Yearly field trials conducted from 2007 to 2011 .

y Overall percent disease control is the mean value of the five trials.

${ }^{\mathrm{z}}$ For each species of Sclerotinia, numbers in each column followed by a different letter are significantly different according to Student's $t$ test. 
depend on its specific properties, such as vapor pressure, polarity, structural properties, water solubility, and so on. Differences in biological interaction between $S$. minor and S. sclerotiorum and any active ingredient should also be considered.

This research demonstrated that the fungicides fluopyram + trifloxystrobin, fluazinam, fluxapyroxad + pyraclostrobin, and boscalid reduced lettuce drop caused by $S$. minor from 61 to $49.6 \%$, and $C$. minitans, iprodione, and boscalid reduced disease caused by S. sclerotiorum from 71.5 to $50.6 \%$, compared with nontreated plants. Also, within the environmental conditions existing during the completion of this field research, one application of boscalid was as effective as two applications for management of lettuce drop caused by $S$. minor and $S$. sclerotiorum. However, one should not underestimate the potential destruction that either of these pathogens can cause in lettuce fields when environmental factors are highly favorable for disease development. Under these conditions, reliance on a single application of boscalid or any other fungicide may not be advisable.

A complicating factor in the use of fungicides to manage lettuce drop is that applications are made early in the crop development cycle, long before disease development occurs. Fungicide labels usually recommend application from plant emergence to after thinning, when plants are small and treatment of soil on the bed surface is the primary focus to inhibit germination of sclerotia in soil. If the field has a recent history of significant lettuce drop or environmental conditions during the growing season are expected to be highly favorable for disease development, then these factors should be incorporated into the decision-making process concerning choice of fungicide to use and number and method of applications to use to achieve the desired level of disease control.
Literature Cited

Anderson, C., Brumhard, B., Ditgens, K., and Reiner, H. 1999. Metabolism of fenhexamid (KBR 2738) in plants, animals, and the environment. Pflanzenschutz-Nachr. Bayer 52:227-251.

Brown, J. G., and Butler, D. 1936. Sclerotiniose in lettuce in Arizona. Univ. Ariz. Agric. Exp. Stn. Bull. 63:475-506.

Hao, J. J., Subbarao, K. V., and Duniway, J. M. 2003. Germination of Sclerotinia minor and S. sclerotiorum sclerotia under various soil moisture and temperature combinations. Phytopathology 93:443-450.

Imolehin, E. D., and Grogan, R. G. 1980. Factors affecting survival of sclerotia, and effects of inoculum density, relative position, and distance of sclerotia from the host on infection of lettuce by Sclerotinia minor. Phytopathology 70:1162-1167.

Kerns, D. L., Matheron, M. E., Palumbo, J. C., Sanchez, C. A., Still, D. W., Tickes, B. R., Umeda, K., and Wilcox, M. A. 1999. Guidelines for Head Lettuce Production in Arizona. Publication no. AZ1099. College of Agriculture and Life Sciences, University of Arizona, Tucson, AZ. https:// cals.arizona.edu/crops/vegetables/cropmgt/az1099.html

Koike, S. T., Gladders, P., and Paulus, A. O. 2007. Vegetable Diseases: A Color Handbook. Academic Press, Boston, MA.

Matheron, M. E., and Matejka, J. C. 1989. In vitro and field comparison of six new fungicides with iprodione and vinclozolin for control of leaf drop of lettuce caused by Sclerotinia sclerotiorum. Plant Dis. 73:727-730.

Matheron, M. E., and Porchas, M. 2004. Activity of boscalid, fenhexamid, fluazinam, fludioxonil, and vinclozolin on growth of Sclerotinia minor and S. sclerotiorum and development of lettuce drop. Plant Dis. 88:665-668.

Matheron, M. E., and Porchas, M. 2016. Comparison of fungicides for management of Sclerotinia lettuce drop, 2015. Plant Dis. Manage. Rep. 10:V012.

Matheron, M. E., and Porchas, M. 2017. Effectiveness of fungicides for managing Sclerotinia drop of lettuce, 2016. Plant Dis. Manage. Rep. 11:V006.

Matheron, M. E., and Porchas, M. 2018. Impact of summer flooding on viability of Sclerotinia minor and S. sclerotiorum sclerotia in soil. Plant Health Prog. 19:15-18.

Wu, B. M., and Subbarao, K. V. 2017. Drop. Pages 35-38 in: Compendium of Lettuce Diseases and Pests, 2nd Ed. K. V. Subbarao, R. M. Davis, R. L. Gilbertson, and R. N. Raid, eds. American Phytopathological Society, St. Paul, MN. 